\title{
Severe Liver Damage and Nonallergic Bronchitis with Eosinophilia in a Patient with Follicular Lymphoma Treated with Bendamustine plus Rituximab
}

\author{
Tatsuro Jo Kensuke Horio \\ Department of Hematology, Japanese Red Cross Society Nagasaki Genbaku Hospital, \\ Nagasaki, Japan
}

\section{Key Words}

Bendamustine $\cdot$ Rituximab $\cdot$ Eosinophilia $\cdot$ Bronchitis · Liver dysfunction

\begin{abstract}
A 66-year-old female with follicular lymphoma developed severe liver dysfunction and nonallergic bronchitis after 1 cycle of treatment with bendamustine and rituximab (BR) therapy. Simultaneously, eosinophilia was observed. Further examination revealed negative results for both hepatitis virus-induced liver damage and lymphoma cell invasion into the liver. No bacterial, fungal, or cytomegaloviral infections of the respiratory tract were observed. The patient was treated with steroid pulse therapy followed by prednisolone with complete resolution of her symptoms. This suggests that eosinophilia induced by the treatment with BR may result in liver dysfunction and nonallergic bronchitis.
\end{abstract}

(C) 2014 S. Karger AG, Basel

\section{Introduction}

Follicular lymphoma (FL) cases comprise approximately 35 and $22 \%$ of all adult nonHodgkin lymphomas in the USA and worldwide, respectively [1]. FL has a chronic relapsingremitting disease course, and there are several treatment options ranging from watchful waiting to chemoimmunotherapy using rituximab in combination with cyclophosphamide, doxorubicin, vincristine, and prednisolone (R-CHOP) [2]. A recent report showed that

Tatsuro Jo, MD, PhD

Department of Hematology, Japanese Red Cross Society

Nagasaki Genbaku Hospital

3-15 Mori-machi, Nagasaki 852-8511 (Japan)

E-Mail firetj@nagasaki-med.jrc.or.jp 
bendamustine and rituximab (BR) therapy was more efficacious and less toxic when compared with R-CHOP therapy [3]. Consequently, BR therapy is being increasingly used in the treatment of FL. Although bendamustine has a favorable tolerability, the most frequent hematologic adverse events associated with its use are leukocytopenia, lymphocytopenia, and neutropenia [4-9]. Common nonhematologic adverse events include nausea, fatigue, and anorexia, and are mainly grade 1 or 2 in severity [4-9]. Here, we report an informative FL case with severe liver dysfunction and nonallergic bronchitis accompanied by eosinophilia that developed following BR therapy.

\section{Case Presentation}

In July 2013, a 66-year-old female was diagnosed with FL (grade 2) using lymph node biopsy of the right supraclavicular lymph node. Based on the Follicular Lymphoma International Prognostic Index score criteria, she had stage IIIa disease (cervical, axillar, abdominal para-aortic, mesenteric, iliac, and inguinal lymph node involvement) and was at high risk ( 3 points based on age, stage, and the number of involved nodal sites). The patient did not report a history of smoking or any allergies. R-CHOP therapy was administered during the first chemotherapy cycle. The patient refused further R-CHOP therapy mainly because of finger numbness, hair loss, and general malaise. Therefore, BR therapy was administered during the second chemotherapy cycle. The patient received 1 cycle of rituximab $\left(375 \mathrm{mg} / \mathrm{m}^{2}\right.$ on day 1$)$ in combination with bendamustine $\left(75 \mathrm{mg} / \mathrm{m}^{2}\right.$ on days 2 and 3).

On day 16 of the BR therapy, the patient developed liver dysfunction with aspartate aminotransferase (AST) and alanine aminotransferase (ALT) levels of 133 and $93 \mathrm{IU} / \mathrm{l}$, respectively. She also developed a severe cough, which resulted in insomnia (grade 3), and was admitted to our hospital for further assessment. As summarized (table 1), her hepatic function had deteriorated further (total bilirubin, $3.1 \mathrm{mg} / \mathrm{dl}$; AST, $800 \mathrm{IU} / \mathrm{l} ;$ ALT, $557 \mathrm{IU} / \mathrm{l}$; alkaline phosphatase, $932 \mathrm{U} / \mathrm{l}$; gamma-glutamyltransferase, $422 \mathrm{U} / \mathrm{l}$; lactate dehydrogenase, $641 \mathrm{U} / \mathrm{l})$. Hepatitis B surface antigen, anti-hepatitis C virus, anti-hepatitis B virus surface antigen, anti-hepatitis B core antigen, and anti-hepatitis A IgM antibodies were all negative. A computed tomography (CT) examination did not show any liver abnormalities (data not shown).

With regard to the severe coughing exhibited by the patient, a CT examination revealed no significant lung abnormalities, demonstrating that she had not been suffering from bacterial pneumonia (data not shown). Anti-mycoplasma IgM antibody and beta-D glucan were both negative. Cytomegalovirus antigens, C7-HRP, C10, and C11 were also absent. The nonspecific IgE level was within normal limits and no specific IgE was detected against 11 antigens that were tested (cocksfoot, Japanese cedar, cat dander, dog dander, egg white, wheat, buckwheat, soy bean, shrimp, Candida albicans, and Derematophagoides farinae) (table 2). The C-reactive protein level was not elevated throughout the course of the patient's illness (table 1). These data indicated that bacterial, fungal or cytomegalovirus infection, and allergic reactions might not have been the cause of the severe coughing. However, an increase in the eosinophil level was observed around 4 weeks after the beginning of the BR therapy, and the eosinophilia was progressive (table 1, fig. 1). Considering these results together, the patient's severe cough was thought to be a result of nonallergic bronchitis due to eosinophilia. The patient was referred to the Department of Respiratory Medicine, and was diagnosed as having bronchitis with eosinophilia. A bronchoscopy was not deemed necessary. 
Subsequently, steroid pulse therapy was administered from day 44 of the BR therapy. Methylprednisolone sodium succinate $(1,000 \mathrm{mg})$ was administered intravenously for 3 consecutive days. On day 47 of the BR therapy, $50 \mathrm{mg}$ of oral prednisolone was administered for 7 days, and the amount of prednisolone was gradually decreased to $0 \mathrm{mg}$ (fig. 1). The severe coughing greatly improved after steroid pulse therapy and diminished very rapidly, and both liver dysfunction and eosinophilia resolved. The patient was discharged from the hospital on day 66 of the BR therapy.

\section{Discussion}

Bendamustine, consisting of a nitrogen mustard moiety bound to a purine-like ring, is an agent with unique alkylating properties. Bendamustine induces DNA damage, apoptosis, and mitotic catastrophe, and shows only a low level or absence of cross-resistance with other alkylating agents [10-13]. The administration of bendamustine in combination with rituximab in the treatment of FL demonstrated a significantly improved progression-free survival compared with R-CHOP therapy, but with a distinct toxicity profile [3]. Significantly fewer hematological toxic effects were noted in patients treated with BR than in those treated with R-CHOP. No alopecia was observed in BR-treated patients, but a drugassociated erythematous skin reaction was more common than in R-CHOP-treated patients. Side effects such as liver damage, bronchitis, and eosinophilia were seldom reported in BRtreated patients.

In this case, the patient was admitted to our hospital for examination because of liver damage and severe coughing. The laboratory data and a CT examination did not indicate that hepatitis viruses or lymphoma cell infiltration into the liver was the cause of the liver damage. Negative laboratory data including a microbiological examination suggested that bacterial and fungal pneumonia, and cytomegalovirus pneumonitis, were also not responsible for the damage (table 2). There was no neutropenia, but lymphocytopenia (up to grade 3) was observed (table 1); therefore, the possibility of viral infectious disease could not be excluded. However, no significant abnormalities were observed in the bilateral lung CT scan examination (data not shown). As eosinophilia was present, the possibility that an allergic reaction was causing the bronchitis was considered. Therefore, nonspecific IgE and specific IgE for 11 antigens were examined, but no positive results were observed, suggesting that nonallergic bronchitis with eosinophilia caused the severe coughing (table 2). We speculated that the patient's severe liver damage and nonallergic bronchitis were the results of eosinophilia, and that steroids would be an effective treatment. As expected, the administration of steroid pulse therapy and prednisolone resulted in the complete resolution of the pathology (fig. 1).

BR is generally a well-tolerated therapy, and eosinophilia seldom occurs as a side effect of the treatment. Gavini et al. [14] reported a bendamustine-induced skin rash with eosinophil infiltration, but Malipatil et al. [15] reported that no eosinophilia was noted in patients with a skin rash. At present, the relationship between BR therapy side effects and eosinophilia is not clear.

\section{Conclusion}

In summary, we reported a case of BR-induced severe liver damage and nonallergic bronchitis with eosinophilia. The efficacy of steroid treatment in this patient indicated that 
eosinophilia resulting from BR therapy might have caused severe liver dysfunction and nonallergic bronchitis. Furthermore, this morbidity caused a lengthy delay in the patient's chemotherapy cycle. Further studies are warranted to clarify the relationship between BR therapy and eosinophilia.

\section{Acknowledgment}

We sincerely thank Maho Nakano for her efforts in editing the manuscript.

\section{Disclosure Statement}

None of the authors has conflicts of interest to declare.

\section{References}

1 Swerdlow SH, Campo E, Harris NL: WHO Classification of Tumours of Haematopoietic and Lymphoid Tissues, ed 4. Lyon, International Agency for Research on Cancer, 2008.

2 National Comprehensive Cancer Network. NCCN guidelines lymphoma, version 1, 2013.

-3 Rummel MJ, Niederle N, Maschmeyer G, Banat GA, von Grunhagen U, et al: Bendamustine plus rituximab versus CHOP plus rituximab as first-line treatment for patients with indolent and mantle-cell lymphomas: an open-label, multicentre, randomised, phase 3 non-inferiority trial. Lancet 2013;381:1203-1210.

4 van der Jagt R: Bendamustine for indolent non-Hodgkin lymphoma in the front-line or relapsed setting: a review of pharmacokinetics and clinical trial outcomes. Expert Rev Hematol 2013;6:525-537.

5 Rummel MJ, AI-Batran SE, Kim SZ, Welslau M, Hecker R, Kofahl-Krause D, Josten KM, Durk H, Rost A, Neise M, von Grunhagen U, Chow KU, Hansmann ML, Hoelzer D, Mitrou PS: Bendamustine plus rituximab is effective and has a favorable toxicity profile in the treatment of mantle cell and low-grade non-Hodgkin's lymphoma. J Clin Oncol 2005;23:3383-3389.

-6 Friedberg JW, Cohen P, Chen L, Robinson KS, Forero-Torres A, La Casce AS, Fayad LE, Bessudo A, Camacho ESA, Williams ME, van der Jagt RH, Oliver JW, Cheson BD: Bendamustine in patients with rituximabrefractory indolent and transformed non-Hodgkin's lymphoma: results from a phase II multicenter, singleagent study. J Clin Oncol 2008;26:204-210.

7 Robinson KS, Williams ME, van der Jagt RH, Cohen P, Herst JA, Tulpule A, Schwartzberg LS, Lemieux B, Cheson BD: Phase II multicenter study of bendamustine plus rituximab in patients with relapsed indolent Bcell and mantle cell non-Hodgkin's lymphoma. J Clin Oncol 2008;26:4473-4479.

8 Cheson BD, Rummel MJ. Bendamustine: rebirth of an old drug. J Clin Oncol 2009;27:1492-1501.

-9 Kahl BS, Bartlett NL, Leonard JP, Chen L, Ganjoo K, Williams ME, Czuczman MS, Robinson KS, Joyce R, van der Jagt RH, Cheson BD: Bendamustine is effective therapy in patients with rituximab-refractory, indolent Bcell non-Hodgkin lymphoma: results from a multicenter study. Cancer 2010;116:106-114.

$\rightarrow 10$ Strumberg D, Harstrick A, Doll K, Hoffmann B, Seeber S: Bendamustine hydrochloride activity against doxorubicin-resistant human breast carcinoma cell lines. Anticancer Drugs 1996;7:415-421.

-11 Leoni LM, Bailey B, Reifert J, Bendall HH, Zeller RW, Corbeil J, Elliott G, Niemeyer CC: Bendamustine (Treanda) displays a distinct pattern of cytotoxicity and unique mechanistic features compared with other alkylating agents. Clin Cancer Res 2008;14:309-317.

-12 Gaul L, Mandl-Weber S, Baumann P, Emmerich B, Schmidmaier R: Bendamustine induces G2 cell cycle arrest and apoptosis in myeloma cells: the role of ATM-Chk2-Cdc25A and ATM-p53-p21-pathways. J Cancer Res Clin Oncol 2008;134:245-253.

13 Roué G, López-Guerra M, Milpied P, Perez-Galan P, Villamor N, Montserrat E, Campo E, Colomer D: Bendamustine is effective in p53-deficient B-cell neoplasms and requires oxidative stress and caspaseindependent signaling. Clin Cancer Res 2008;14:6907-6915.

14 Gavini A, Telang GH, Olszewski AJ: Generalized purpuric drug exanthema with hemorrhagic plaques following bendamustine chemotherapy in a patient with B-prolymphocytic leukemia. Int J Hematol 2012;95:311-314.

15 Malipatil B, Ganesan P, Sundersingh S, Sager TG: Preliminary experience with the use of bendamustine: a peculiar skin rash as the commonest side effect. Hematol Oncol Stem Cell Ther 2011;4:157-160. 
Jo and Horio: Severe Liver Damage and Nonallergic Bronchitis with Eosinophilia in a Patient with Follicular Lymphoma Treated with Bendamustine plus Rituximab

Table 1. Laboratory data

\begin{tabular}{|c|c|c|c|c|c|c|c|c|c|c|c|}
\hline Days after BR treatment & -2 & 9 & 16 & 28 & 31 & 34 & 4144 & 50 & 58 & 64 & 90 \\
\hline T-Bil, mg/dl & 0.6 & 2.9 & 0.7 & 1.4 & 3.1 & 5.6 & 6.24 .5 & 2.2 & 1.1 & 1.2 & 1.0 \\
\hline D-Bil, mg/dl & 0.1 & 0.3 & 0.1 & 0.5 & 2.1 & 4.4 & ND 2.7 & 0.5 & 0.2 & 0.2 & 0.1 \\
\hline AST, IU/l & 17 & 17 & 133 & 525 & 800 & 789 & 609399 & 18 & 14 & 11 & 15 \\
\hline ALT, IU/l & 12 & 12 & 93 & 477 & 557 & 577 & 466365 & 73 & 23 & 16 & 13 \\
\hline ALP, U/l & 285 & 268 & 274 & 947 & 932 & 900 & 731693 & 409 & 266 & 250 & 242 \\
\hline GGT, U/l & 26 & 30 & 35 & 380 & 422 & 396 & ND 229 & 152 & 98 & 78 & 43 \\
\hline LDH, U/l & 179 & 149 & 279 & 579 & 641 & 544 & 392293 & 131 & 148 & 177 & ND \\
\hline CRP, mg/dl & 0.31 & 0.10 & 0.35 & 3.43 & 0.55 & 0.32 & 0.300 .20 & 0.02 & 0.18 & 0.07 & 1.89 \\
\hline $\mathrm{WBC}, / \mathrm{l} \times 10^{9}$ & 3.4 & 5.1 & 3.8 & 6.1 & 4.8 & 4.4 & $4.9 \quad 4.5$ & 5.7 & 11.7 & 7.5 & 3.6 \\
\hline EOS, \% & 3 & 7 & 1 & 2 & 18 & 19 & $36 \quad 34$ & 5 & 1.5 & 1 & 0 \\
\hline Neut, \% & 61 & 78 & 73 & 79 & 49.5 & 51 & $32 \quad 32$ & 78 & 84.5 & 86 & 49 \\
\hline Lym, \% & 24 & 8 & 16 & 12 & 18 & 7 & $10 \quad 19$ & 6 & 7.5 & 7 & 28 \\
\hline
\end{tabular}

T-Bil = Total bilirubin; D-Bil = direct bilirubin; ALP = alkaline phosphatase; GGT = gamma-glutamyltransferase; LDH = lactate dehydrogenase; $\mathrm{CRP}$ = C-reactive protein; $\mathrm{WBC}=$ white blood cells; $\mathrm{EOS}=$ eosinophils; Neut = neutrophils; Lym = lymphocytes; ND = not done.

Table 2. Bronchitis evaluation

\begin{tabular}{lll}
\hline $\begin{array}{l}\text { Cytomegalo- } \\
\text { virus }\end{array}$ & C7-HRP & $\begin{array}{l}\text { negative } \\
\text { negative } \\
\text { negative }\end{array}$ \\
\hline $\begin{array}{lll}\text { Mycoplasma } \\
\text { pneumoniae }\end{array}$ & anti-mycoplasma IgM & negative \\
\hline Fungus & beta-D glucan & \\
\hline IgE & nonspecific IgE & $<2.81 \mathrm{pg} / \mathrm{ml}$ \\
\hline & specific IgE anti-cocksfoot & $\leq 5.0 \mathrm{IU} / \mathrm{ml}$ \\
& specific IgE anti-Japanese cedar & $<0.10 \mathrm{UA} / \mathrm{ml}$ \\
& specific IgE anti-cat dander & $<0.10 \mathrm{UA} / \mathrm{ml}$ \\
& specific IgE anti-dog dander & $<0.10 \mathrm{UA} / \mathrm{ml} / \mathrm{ml}$ \\
& specific IgE anti-egg white & $<0.10 \mathrm{UA} / \mathrm{ml}$ \\
& specific IgE anti-wheat & $<0.10 \mathrm{UA} / \mathrm{ml}$ \\
& specific IgE anti-buckwheat & $<0.10 \mathrm{UA} / \mathrm{ml}$ \\
& specific IgE anti-soy bean & $<0.10 \mathrm{UA} / \mathrm{ml}$ \\
& specific IgE anti-shrimp & $<0.10 \mathrm{UA} / \mathrm{ml}$ \\
& specific IgE anti-C. albicans & $<0.10 \mathrm{UA} / \mathrm{ml}$ \\
specific IgE anti-D. farinae & $<0.10 \mathrm{UA} / \mathrm{ml}$ \\
\hline
\end{tabular}


Jo and Horio: Severe Liver Damage and Nonallergic Bronchitis with Eosinophilia in a Patient with Follicular Lymphoma Treated with Bendamustine plus Rituximab

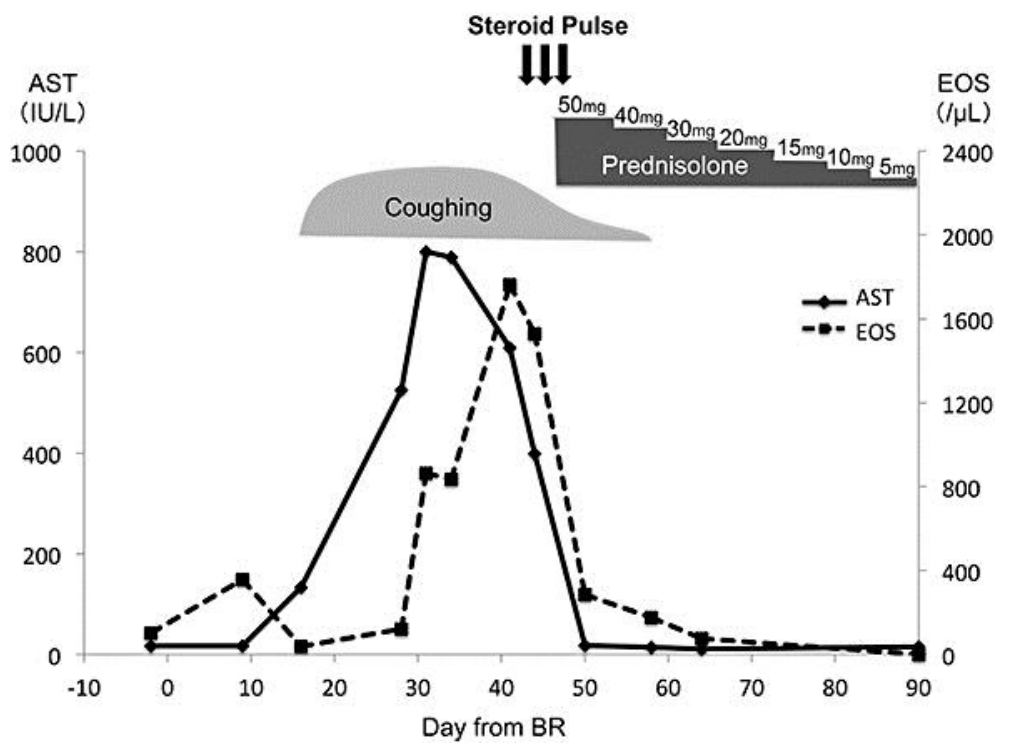

Fig. 1. The clinical course of the patient. Methylprednisolone sodium succinate $(1,000 \mathrm{mg})$ was administered on days 44-46 of the BR therapy (steroid pulse). Thereafter, $50 \mathrm{mg}$ of prednisolone was administered, starting on day 47 and it was gradually tapered off to $0 \mathrm{mg}$. EOS = Eosinophils. 